\title{
Relación entre Factores Individuales y Familiares de Riesgo para Desórdenes Alimenticios en Alumnos de Enseñanza Media ${ }^{1}$
}

\section{The Relation Among Individual and Family Risk Variables in Feeding Disorders of Middle School Children}

\author{
González, L*., Hidalgo, M., Hurtado, M., Nova, C. y Venegas, M.
}

\begin{abstract}
Resumen
La presente investigación explora la relación entre los distintos factores de riesgo de la anorexia nerviosa. Específicamente, considera edad, peso, altura, autoestima, depresión, cohesión familiar, conflicto familiar, adaptabilidad familiar. El análisis bivariado arroja las correlaciones más significativas entre autoestima y depresión (-0.728), Depresión y Anorexia (0.710), Autoestima y Anorexia (-0.699). También aparecen como significativas las correlaciones entre Anorexia Nerviosa y conflicto (0.406), cohesión (-0.289) y peso (0.285). En el análisis multivariado, la predicción de riesgo está determinada por Depresión, Autoestima, Peso, Conflicto, Cohesión, Altura y el tipo de establecimiento. Además, se discuten resultados y posibles líneas de investigación a partir de los hallazgos.
\end{abstract}

\begin{abstract}
The present research explores the relationship between the various risk factors of anorexia nervosa. Specifically considers age, weight, height, depression, family cohesion, family conflict, family adaptability. The bivariate analyses shows the most significant correlations between self-esteem and depression (-0.728), depression and anorexia (0.710), self-esteem and anorexia (-0.699). It also appears significant the correlations between anorexia nervosa and conflict (0.406), cohesion (-0.289) and weight (0.285). In the multivariate analysis, depression, self-esteem, weight, conflict, cohesion, height and the type of high-school, predict the anorexia risk. Results and possible lines for future investigations are discussed.
\end{abstract}

\footnotetext{
1 La presente investigación no habría sido posible sin la ilimitada colaboración de todos aquellos colegios y liceos que participaron en ella, de la Dirección de Educación Municipal de Concepción, de la SEREMI de Educación, y del profesor Roberto Melipillán, a todos quienes debemos nuestros agradecimientos.

*Psicólogo, Docente Universidad San Sebastián.e-mail: lgonzale@mater.uss.cl
} 


\section{Introducción}

Durante las últimas tres décadas, los trastornos del hábito del comer, principalmente la Anorexia Nerviosa, han sido foco de atención creciente por parte de variadas disciplinas médicas y no médicas (Behar, 1986), debido al aumento progresivo que la presencia de la patología ha tenido en las consultas clínicas.

La constatación del creciente aumento de la incidencia del trastorno, puede significarse en el contexto del rol preponderante que ha adquirido el cuerpo, como distinción social y como medio de competitividad, de afirmación y reconocimiento (Chinchilla, 1995). Todo esto es propio de la cultura occidental, donde se sobrevalora la apariencia física, especialmente la delgadez, la que representa el valor estético estereotipado.

El cuadro clínico aparece fundamentalmente en jóvenes adolescentes, entre 12 a 25 años, siendo infrecuente el comienzo por encima de los 25 años de edad. La distribución por sexos muestra que aproximadamente entre el $85 \%$ y $95 \%$ de los casos son mujeres, dentro de las cuales, se han identificado grupos de personas o profesionales más vulnerables a este trastorno, tales como gimnastas, bailarinas y modelos de pasarelas (Chinchilla, 1995).

A pesar del interés en torno a la problemática de la Anorexia Nerviosa y los diversos modelos teóricos que intentan explicarla, la naturaleza exacta de esta patología sigue siendo considerada un misterio. Sin embargo, ha sido posible, basándose en revisiones bibliográficas y en el análisis de investigaciones nacionales y extranjeras, identificar ciertos factores biológicos, psicológicos y ambientales, decisivos en la manifestación de este cuadro clínico, constatándose un modelo etiopatogénico biopsicosocial (Chinchilla, 1995).
En el ámbito nacional, existen escasas investigaciones referidas al tema de la Anorexia Nerviosa, donde destacan los estudios realizados por la Dra. Rosa Behar en la región de Valparaíso, y que han abordado principalmente aspectos clínicos y epidemiológicos de la patología, identificación de la población de riesgo, características del trastorno y estudios de factores tales como perfeccionismo e insatisfacción corporal.

Sin embargo, no hay estudios que hayan explorado la interacción existente entre factores de riesgo individuales y familiares, foco en el cual la presente investigación pretende centrarse, para así contribuir a la construcción de un perfil de riesgo para Anorexia Nerviosa.

\section{Definición de Anorexia Nerviosa}

La Anorexia, en primera instancia, puede ser conceptualizada como la falta o disminución del apetito. Sí sólo nos quedaramos con esta definición, no podría ser catalogada como una patología independiente, sino más bien como problema asociado a otros trastornos. Precisamente, por esta razón se habla de Anorexia Nerviosa, donde el término nervioso hace referencia a la naturaleza psicológica del trastorno y no a la pérdida de apetito.

Son personas obsesionadas con el tamaño de sus cuerpos, se sienten obesas aún cuando con frecuencia están delgadas e incluso demacradas. Se caracterizan por presentar un pensamiento normal, el que se torna irracional en todo lo relativo a la masa corporal.

También existen ciertos cambios fisiológicos y bioquímicos importantes asociados a la Anorexia Nerviosa, como el cese de los períodos menstruales y síntomas de inanición, manifestados en anemia, piel seca y 
úlceras en la boca, que de continuar, generan consecuencias graves, tales como ritmos cardíacos anormales, descalcificación, problemas motores, del habla, audición y visión.

Beumont, George \& Smart (1976), citados en Belloch \& cols., 1995, clasificaron al trastorno en dos tipos: la Anorexia Restrictiva, donde la pérdida de peso se consigue exclusivamente haciendo dieta, ayunando o realizando ejercicios físicos extenuantes y la Anorexia Compulsiva o Purgativa, en la cual la persona recurre regularmente a atracones y/o purgas (provocación de vómito o uso de laxantes, diuréticos o edemas). Así también, hay casos en que no hay presencia de atracones, pero las personas llevan a cabo las purgas aún después de haber ingerido pequeñas cantidades de alimento.

Como características asociadas a los subtipos, se ha encontrado que las anoréxicas restrictivas presentan mayor perfeccionismo, rigidez, hiperresponsabilidad, sentimientos de ineficacia (Garfinkel, Moldofsky \& Garner, 1980, citados en Belloch \& cols., 1995), negación de la sensación de hambre y enfermedad (Morandé, 1999). En cambio, las anoréxicas purgativas manifiestan sobrepeso premórbido, impulsividad, reacciones distímicas, labilidad emocional, conductas adictivas (Garfinkel \& cols., 1980, citados en Belloch \& cols., 1995), falta de voluntad y tendencia a la depresión (Morandé, 1999).

Para Bruch (1973) existen 3 características esenciales manifestadas por las pacientes con Anorexia Nerviosa, citado en Ajuriaguerra (1997): la distorsión en la percepción de la imagen corporal, sin conciencia en la delgadez alcanzada, la percepción distorsionada de los estímulos propioceptivos y el sentimiento general de ineficacia personal.
En resumen, la Anorexia Nerviosa puede conceptualizarse en un continuo relacionado con un excesivo autocontrol de la ingestión de alimentos. Cuando se presenta en ellas una ruptura de este mecanismo, se restaura tal condición por medio de la utilización de ciertos medios, como por ejemplo, el vómito o la restricción de la ingesta alimenticia (Ollendick \& Hersen, 1993).

\section{Características clínicas de Anorexia Nerviosa}

La característica central de la Anorexia Nerviosa es el rechazo a mantener el peso corporal por encima del valor mínimo normal para la talla y edad de la adolescente (Marsellach, 2000). Todo esto está asociado al temor a engordar, lo que se convierte en el centro de todas sus preocupaciones, perturbando gravemente su vida. Generalmente este tipo de trastorno suele iniciarse después que la adolescente recibe algún comentario, directo o indirecto, sobre su supuesto sobrepeso, lo que la conduce a iniciar una restricción alimenticia tanto en cantidad como calidad, adhiriéndose a las más rígidas consignas que se han fijado como metas (Belloch \& cols., 1995).

En este deseo por adelgazar se fijan un margen de seguridad, estableciendo un peso límite a mantener, el que suelen bajar con el objeto de evitar cualquier aumento que esté fuera de sus cálculos. Una vez que logrado el peso deseado, siguen reduciendo la cantidad de calorías que consumen diariamente (Belloch \& cols., 1995). A pesar del intenso deseo por comer, el horror que les causa sentirse controladas por ellos, las hace recurrir a medios para mitigarlo, como beber abundante agua o utilización de purgas. Estos comportamientos por lo general se complementan con una actividad física excesiva. 
Otra manifestación importante de la Anorexia Nerviosa es la distorsión de la imagen corporal, cuyo inicio se remonta a la adolescencia, en respuesta a los cambios biopsicológicos desarrollados en esta etapa: aparición de caracteres sexuales secundarios, el aumento del peso a expensas del tejido adiposo y la poca información con que cuentan respecto a esta etapa. Así mismo, surge la necesidad de establecer una identidad y la lucha por lograr la autonomía, que puede conseguirse a través de una transformación de los hábitos alimentarios, característicos de la tradición familiar (Behar, 1998).

\section{Factores Predisponentes de la Anorexia Nerviosa}

La Anorexia Nerviosa es un trastorno de etiología multifactorial (Fairburn \& Cooper, 1984; Kaye \& Weltzin, 1991; Campbell, 1995, citados en Morandé, 1999), ligado a la organización genético-biológi- ca, estructura de personalidad, organización familiar, sistemas de creencias, crianza y presión social. Para los fines del presente artículo no se abordarán las hipótesis explicativas para el trastorno elaboradas desde las distintas escuelas (sistémicas, cognitivas, dinámicas, etc.), aún cuando son fundamentales para un análisis de éste.

En busca de una mejor comprensión de su origen y desarrollo, la literatura especializada ha establecido una distinción entre factores de riesgo, predisponentes, desencadenantes y de mantención. En cuanto a los factores de riesgo (clasificación ocupada por Morandé, 1999), se señalan, conducta de dieta, sexo femenino y etapa adolescente.

A continuación se presentan 3 tablas comparativas en relación a factores predisponentes (Tabla 1), desencadenantes (Tabla 2) y de mantención (Tabla 3) según Chinchilla (1995), Morandé (1999) y Toro \& Vilardell (1987, citados en Belloch \& cols.,1995).

Tabla 1.

Factores Predisponentes

Morandé (1999) Chinchilla (1995)

Toro y Vilardell (1987)*

\begin{tabular}{lll}
\hline - Predisposición genética & - Predisposición genética & - Factores genéticos \\
- Obesidad premórbida & - Sexo femenino & - Etapa adolescente \\
- Enfermedad crónica in- & - Clase media alta & - Sexo femenino \\
fantil & - Dependencia parental & - Trastorno afectivo \\
- Historia de depresión o & - Identidad personal & - Introversión/inestabilidad \\
trastorno obsesivo & incompleta & - Obesidad \\
infantil & - Disminución de la & - Nivel social medio/alto \\
- Familia muy sensible a & actividad sexual & - Familiares con trastorno afectivo \\
las apariencias & - Dificultad para ser & - Familiares con adicciones \\
- Perfeccionismo & independiente & - Familiares con trastorno de la \\
- Aceptación de normas & - Déficit en pensamientos con- & ingesta \\
sociales & ceptuales y razonamiento & - Obesidad materna \\
- Aparente autonomía & abstracto & - Valores estéticos \\
& - Períodos de negativismo & dominantes \\
\hline
\end{tabular}

* Toro E Vilardell, 1987, citados en Belloch \& cols., 1995. 
Tabla 2.

Factores Descencadenantes

Morandé (1999)

Chinchilla (1995)

Toro y Vilardell (1987)*

- Ayuno o dieta adelgazante

- Alteraciones neuroendocrinas

- Vómitos autoinducidos

- Uso de laxantes u otras sustancias para perder peso

- Ejercicio físico excesivo

- Enfermedad física con baja de peso

- Subida significativa de peso

- Mediadores en conflictos familiares

- Familia sobreprotectora

- Matrimonio

- Muerte de padre

- Malestar o insatisfacción emocional

- Dieta

- Pérdida amorosa

- Ruptura con amigos

- Cambio de ciclo escolar o colegio

- Agresión física o sexual

- Separación de la familia

- Conflictos de los padres

- Enfermedad o muerte de familiar

- Cambios corporales

- Separación y pérdidas

- Rupturas conyugales del padre

- Contactos sexuales

- Incremento rápidos de peso

- Críticas sobre el cuerpo

- Enfermedad adelgazante

- Traumatismo desfigurador

- Incremento en la actividad física

- Acontecimientos vitales

* Toro \& Vilardell, 1987, citados en Belloch \& cols., 1995.

Tabla 3.

Factores Mantención

\begin{tabular}{lll}
\multicolumn{1}{c}{ Morandé (1999) } & Chinchilla (1995) & Toro y Vilardell (1987)* \\
\hline - Ayuno o dieta adelgazante & - Alteraciones hormonales & - Cambios corporales \\
- Ayuno-desnutrición & - Autoexigencia profesional & - Consecuencias de la \\
- Vómito como purgación & - Responsables y vigilantes de & inanición \\
- Uso masivo de laxantes & obligaciones & - Interacción familiar \\
- Ejercicio físico compulsivo & - Dificultad para expresar con & - Aislamiento social \\
- Pérdida sostenida de peso & palabras afectos y emociones & - Cogniciones \\
- Digestiones lentas & - Influencias externas en acti- & anoréxicas \\
- Desaparición del hambre & tudes hacia la comida & - Actividad física \\
- Ausencia o negación de fatiga & - Reducción de carbohidratos & excesiva \\
- Estudios o trabajo compulsivo & y grasas & \\
- Terror a subir de peso & - Hiperactividad & \\
- Obsesión de adelgazar & - Pensamientos recurrentes & \\
- Disociación mental & hacia la comida & \\
- Distorsión de la imagen corporal & Amplios cambios de humor & \\
- Negación de enfermedad & & \\
- Interacción familiar ante enfermedad & & \\
- Aislamiento social & & \\
- Consumo de drogas & & \\
- Omnipotencia & & \\
- Refuerzo social por bajar de peso & & \\
- Ambivalencia ante trastorno & & \\
\hline
\end{tabular}

* Toro E Vilardell, 1987, citados en Belloch \& cols., 1995. 
Consecuentemente con los objetivos de la investigación, se analizarán detalladamente los factores considerados predisponentes de la patología, divididos en individuales y familiares.

\section{Factores Familiares}

\section{Evitación de Conflictos}

Es común encontrar en las familias de pacientes anoréxicas un funcionamiento que se caracteriza por una combinación de manifestaciones con un cierto grado de patología, como el aglutinamiento, la sobreprotección y la rigidez, lo que trae como consecuencia una baja tolerancia del sistema para enfrentar y manejar adecuadamente situaciones estresantes (Rausch \& Bay, 1997).

La estructura familiar particular determinará la forma en que cada una de ellas evitará un conflicto. Como consecuencia negativa de esta situación no se genera una instancia en donde se produzca una negociación explícita de las diferencias; todo esto conlleva a que los problemas que surjan al interior de la familia queden sin resolver, representando una amenaza constante que activa una y otra vez los circuitos de evitación del sistema. Esto lleva a que la familia se conduzca como si no existieran problemas, otorgándole una imagen de sistema perfecto hacia el exterior.

En estas familias, la fuente de la evitación puede ser variada y complementaria; se puede dar el caso que uno de los cónyuges sea el evitador, en otros, la familia se caracteriza por la existencia constante de discusiones entre sus miembros, pero las interrupciones típicas y los constantes cambios de temas que caracterizan a los sistemas aglutinados, terminan por diluir cualquier conflicto antes de que se pueda llegar a plantear una solución para resolverlo. Otros sistemas simplemente negaran la existencia de cualquier problema o conflicto (Rausch \& Bay, 1997). Toda esta evitación trae como consecuencia un aumento en la intensidad, peligrosidad y mantenimiento de los síntomas, además de incrementar la falta de conciencia de la adolescente acerca de su problema, la cual actúa como si su situación fuera normal, poniendo cada vez más en peligro su salud.

\section{Paciente designado en los conflictos familiares}

"Se refiere a la utilización del hijo como un agente, mediante el cual se pueden desviar los conflictos conyugales, como una manera de mantener un equilibrio en el subsistema conyugal" (Rausch \& Bay, 1997:29). Esta característica se expresa por medio de tres tipos de coaliciones. En la primera, lo que la hija diga o haga significará que ella tomará partido por uno de los progenitores, produciéndose una alianza o coalición de un padre en contra del otro, situación que recibe el nombre de triangulación. El segundo tipo de coalición padre- hija o madre-hija, se diferencia del anterior por la estabilidad temporal del vínculo entre uno de los progenitores y su hija. En el último patrón denominado desviación de la díada conyugal, la interacción se presenta unida en una postura de protección o acusación frente a la hija enferma y sus conflictos, definiéndola como el único problema familiar. Lo que preocupa a los padres, en estos casos, son las obligaciones parentales que absorben a la pareja, de tal modo que pueden llegar a ignorar cualquier señal de tensión alrededor de ésta, utilizando como "chivo expiatorio" a la hija, de manera tal de no enfrentar directamente la situación como un problema conyugal (Rausch \& Bay, 1997). 


\section{Limites Familiares}

Hace referencia a la dinámica familiar y los patrones de interacción que se establecen entre sus miembros. La literatura existente, señala como condiciones familiares importantes la sobreprotección y el aglutinamiento.

En familias caracterizadas por patrones de interacción sobreprotectores, no es posible apreciar una clara delimitación de la individualidad de cada uno de los miembros, más bien es común observar altos grados de cohesión entre estos. La sobreprotección de los padres retarda el desarrollo de la autonomía de los hijos, siendo habitual que inhiban la participación de ellos en actividades que abarquen esferas fuera del ámbito del hogar, de manera que no se educa a los hijos para enfrentarse a la vida, existiendo notables carencias de habilidades para tomar decisiones. El tipo de interacciones característico de estas familias conlleva a que los hijos, especialmente el paciente índice, sienta gran preocupación en proteger a la familia, lo cual generalmente logra, manteniendo o intensificando su sintomatología (Rausch \& Bay, 1997).

Aglutinamiento se refiere a una forma de proximidad de tal intensidad, que hace que cualquier alteración repercuta en toda la estructura familiar. Esto se puede observar en la interdependencia de relaciones, intrusiones constantes en los pensamientos y sentimientos del otro, que hace que el sentido de identidad personal se diluya y se reemplace por la proximidad entre las percepciones individuales y familiares (Rausch \& Bay 1997). Con esta modalidad de funcionamiento es común que frente a un conflicto se vayan produciendo alianzas dentro del sistema. Los límites individuales son tan difusos entre los miembros, que el espacio vital de la persona es frecuentemente transgredido, al igual que los subsistemas conyugales, parentales y fraternos, todo esto por lo difuso de sus límites. Al carecer de un subsistema parental eficaz y claramente definido, es muy común que los padres presenten distintas expectativas y metas para cada uno de sus hijos.

\section{Rigidez}

Las familias rígidas operan como sistemas con límites poco permeables, lo que les impide tener la posibilidad de autorregular su permanencia y viabilidad, ya que poseen límites impermeables en su relación con el medio. Esta inflexibilidad sólo permite un repertorio limitado de respuestas interpersonales y les dificulta modificar sus pautas de interacción ante crisis evolutivas normales (Minuchin, Rosman \& Baker, 1978 citados en Rausch \& Bay, 1997), favoreciendo una adaptación inadecuada a las exigencias que les impone el desarrollo del ciclo de vida familiar. Producto de la falta de flexibilidad, estas familias desarrollan conductas de evitación, para lo cual resulta sumamente útil el portador del síntoma (Rausch \& Bay, 1997).

Una característica común a estas familias es que son vistas por los otros sin mayores dificultades o conflictos, con la excepción de la enfermedad de la hija, negando enfáticamente cualquier necesidad de cambio en la familia ya que los problemas son atribuidos sólo al paciente índice.

\section{Factores Individuales}

\section{Depresión}

No es infrecuente que la Anorexia Nerviosa y en general, los trastornos alimenticios, vayan asociados con la depresión, pero no se ha podido establecer con exactitud si ésta es causa o resultado de la patología.

Sobre esto, ha existido una controversia entre los investigadores acerca del rol que tiene la depresión en la etiología de los tras- 
tornos alimenticios. De acuerdo a una investigación llevada a cabo por Leon, Fulkerson, Perry \& Cudeck (1993), cuando la depresión es diagnosticada en el transcurso de la Anorexia Nerviosa, no es considerada como causa del trastorno sino más bien, algo secundario. Posteriormente, los mismos investigadores realizaron un estudio con alumnas de secundaria, durante un período de 6 meses, concluyendo que no hay una relación de causalidad predominante entre la presencia de síntomas depresivos y los desórdenes alimenticios.

Sin embargo, en una investigación llevada a cabo el año 1997 por Stice, Hayward, Cameron, Killen \& Taylor (2000), se encontró que los desórdenes alimenticios tendrían una relación temporal en el desarrollo de la depresión. La insatisfacción corporal y la dieta estricta, serían factores predictores importantes en el desarrollo futuro de depresión. Sus conclusiones se basan en que la imagen corporal es una dimensión a partir de la cual las mujeres occidentales son evaluadas, por lo tanto, si éstas no se sienten satisfechas con su propio cuerpo, buscarán por todos los medios, lograr alcanzar la imagen perfecta (desde su punto de vista), surgiendo aquí el segundo síntoma, que corresponde a las dietas estrictas a las que se someten. En el caso de fracasar en sus intentos pueden caer en un estado de angustia y desesperación tal, que las lleve a desarrollar un trastorno depresivo (Dorr, 1995).

De acuerdo a diferentes investigaciones, entre un $40 \%$ y un $80 \%$ de las pacientes que presentan alguno de los trastornos alimenticios manifiestan simultáneamente una depresión; la cual es a su vez, un trastorno común en las familias de pacientes con trastornos alimenticios. Expertos en el área plantean que la depresión no desempeña un papel causal en la anorexia, ya que se ha comprobado que ésta continua presente aún cuando a las pacientes se les administran antidepresivos como única forma de tratamiento. Además, la gravedad de la Anorexia Nerviosa tampoco se correlaciona con la gravedad de cualquier tipo de depresión existente. Sin embargo, es común que la depresión tienda a mejorar una vez que las pacientes anoréxicas comiencen a aumentar su peso (Del Canto, 2001)

Se han encontrado ciertas alteraciones a nivel neuroendocrino en los casos de pacientes anoréxicas y con depresión. Se ha descubierto en algunas pacientes con Anorexia Nerviosa cantidades bajas de ciertos neurotransmisores (serotonina y norepinefrina), mensajeros químicos cerebrales, que suelen permanecer en niveles bajos una vez que la paciente ha recuperado su peso. Estos niveles anormales de neurotransmisores suelen también encontrarse en pacientes depresivos. Estudios recientes han revelado bajos niveles sanguíneos del aminoácido triptófano, el que se encuentra en ciertos alimentos y que es fundamental para la producción de serotonina, lo que puede ser una causa de depresión. Se plantea hipotéticamente que aquellas personas que comen excesivamente después de haber realizado una dieta severa pueden estar haciéndolo como una respuesta a este estado emocional de estímulo proteínico. Estas alteraciones neuroendocrinas, que pueden conllevar a una depresión, suelen estar asociadas a una nutrición deficitaria, la realización de ejercicios físicos en forma persistente y exagerada yo a la falta de recursos y habilidades para enfrentar situaciones estresantes (Del Canto, 2001).

En definitiva, aunque exista una relación entre la Anorexia Nerviosa y depresión, pareciera que la primera no es una consecuencia directa de la segunda, sino que más bien la depresión puede ser un factor que predisponga al cuadro clínico, lo cual agrava aún más la situación de la paciente. Este impacto que tiene la depresión sobre la 
Anorexia Nerviosa es debido a que las personas depresivas suelen experimentar y ser más susceptibles a sentimientos de baja autoestima, lo cual contribuye al desarrollo del trastorno alimenticio (Del Canto, 2001).

\section{Obesidad Premórbida}

Hoy en día tanto la obesidad como la Anorexia Nerviosa se han convertido en importantes problemas de salud, como consecuencia del aumento en la prevalencia de ambos trastornos. Durante la última década se ha observado una disminución en la edad de manifestación de la obesidad. Consecuentemente es posible apreciar, cada vez con mayor frecuencia, a niños con presencia de esta patología, los que generalmente se transforman en el centro de las burlas de sus pares. Esto puede llegar a tal grado que la persona se sienta incómoda con su apariencia y busque por todos los medios modificarla (Marsellach, 2000).

La intención de una persona por modificar su cuerpo y el grado de ésta va a depender de las características individuales de cada una. Una persona que es "normal", adelgaza hasta sin poner en peligro su integridad física, pero una persona que posee ciertas características patológicas, como por ejemplo una alteración de la percepción corporal, disminuye su peso hasta el extremo de lograr una figura esquelética, sin llegar a tomar conciencia de su real condición. En otras palabras, no todas las personas que presentan cierto grado de obesidad llegarán a desarrollar una Anorexia Nerviosa, sino que esta condición debe ir asociada a ciertas características personales que aumenten la incidencia.

Por un lado, Morandé en España en 1999 constató que un $10 \%$ de sus pacientes anoréxicas presentaron obesidad previa al desarrollo de la patología alimenticia y por otro, Behar, Fernández y Hernández, en 1994, estimaron que el $41 \%$ de adolescentes diagnosticadas con obesidad, tienen la probabilidad de desarrollar una patología alimentaria.

\section{Dependencia Afectiva}

En general esta característica se refiere a una capacidad limitada de desempeñarse en forma independiente, lo que en la persona anoréxica se atribuye a un déficit en la autonomía y dominio de su propio cuerpo, que le otorga un sentido de ineficacia personal. Al respecto, "las pacientes se perciben a sí mismas como habiendo perdido el control de su conducta, sus necesidades e impulsos, como no siendo dueñas de su propio cuerpo, como careciendo de un centro de gravedad. Por el contrario, se sienten bajo la influencia de fuerzas externas" (Bruch, 1982, citado en Rausch \& Bay, 1997: 25). Este déficit en la identidad personal puede derivarse en dificultades mayores cuando carecen de una orientación parental o se enfrentan a nuevas demandas ambientales. Es esto mismo lo que le da a la persona una baja autoestima, una falta de seguridad y un perfeccionismo excesivo en todas las acciones que desempeña, incluyendo su propio cuerpo. Igualmente, se autoexigen demasiado, en el sentido de conducirse de una forma que no permita errores en su accionar.

Estudios realizados por Rogers \& Petrie (1996) y Leon, Fulkerson, Perry \& Earli-Zald (1995) confirman la predictividad de la dependencia sobre la Anorexia Nerviosa, concluyendo que mujeres con altos niveles de conducta y actitudes anoréxicas, presentan mayor dependencia emocional hacia otros. Estos hallazgos son explicados a través de teorías psicodinámicas donde se establece que la dependencia se manifiesta para mantener relaciones personales cercanas, especialmente con la madre. 
Los agentes socializadores se encargan de educar desde temprana edad a las mujeres para que internalicen conductas específicas, como por ejemplo, pasividad y dependencia, mientras que comportamientos como la independencia y asertividad son poco estimulados. Como parte de esta socialización, la mujer aprende a suprimir sus necesidades en beneficio de la satisfacción de otros (Behar, 1996). Las mujeres con una predisposición a desarrollar Anorexia Nerviosa no manifiestan directamente su descontento hacia las pautas sociales, sino que por el contrario, dejan de comer como una forma de establecer un control sobre sus vidas y manejar la hostilidad.

Por otra parte, estas personas desarrollan escasas habilidades sociales, lo que les impide establecer adecuadas redes de apoyo, necesarias para el afrontamiento de situaciones conflictivas. Esto está cimentado en una notoria inmadurez de su comportamiento, a nivel cognitivo, que las lleva por ejemplo, a una inhibición emocional y sexual, siendo percibida como "niñas buenas". Pero es el carecer de un sentido de identidad lo que expone a estas personas a una sensibilidad ante el fracaso y toda crítica, no importando lo leve que ésta sea, reforzando su creencia de que no son "tan buenas"' (Del Canto, 2001).

En contraposición a lo anterior, en una investigación para determinar la personalidad y conductas vulnerables asociadas con el nivel de riesgo para desórdenes alimenticios en adolescentes, donde se hipotetizó que la baja autonomía era un factor predictor para los trastornos alimenticios, se concluyó que ésta no aportaba evidencias suficientes para ser considerada un factor de riesgo (Rogers \& Petrie, 1996).

\section{Rasgos de personalidad}

Históricamente han existido diferencias en los intentos por relacionar la Anorexia
Nerviosa con un perfil específico de personalidad. Algunos autores plantean una conexión sobrevalorada entre patología de la alimentación y personalidad (Strober, 1980; Aronson, Fredman \& Gabriel, 1990, cit. en Rogers \& Petrie, 1996). Por el contrario, otros, como Garner \& Garfinkel (1982), citados en Leon \& cols., 1995, señalan que no existe un perfil de personalidad que predisponga a la mujer a desarrollar Anorexia Nerviosa. En la misma línea, se señala que no existe una influencia causal entre el desarrollo de trastornos de la conducta alimenticia y rasgos de personalidad, sino que la relación se debe a una tercera variable predisponente a la Anorexia Nerviosa, que incrementa el riesgo a padecer una o ambas patologías (Vitousek, 1994 \& Wonderlich, 1992, citados en Wonderlich \& Mitchell, 2001). Un planteamiento intermedio corresponde al de Orbach (1986), citado en Rogers y Petrie (1996), quien establece una descripción de personalidad anoréxica, la cual está relacionada con el rol de la mujer en la sociedad.

Las pacientes anoréxicas no presentan un perfil único de personalidad, sin embargo, es posible encontrar ciertos rasgos comunes en ellas, manifestados en sus conductas e interacciones con otros. Orbach (1986), citado en Rogers y Petrie (1996), señala un perfil específico de personalidad asociado con este desorden: obsesividad, dependencia, sobrecontrol de hostilidad y déficit de asertividad.

La focalización en el logro es un aspecto central de la conducta obsesiva - compulsiva y la delgadez corporal se convierte, de esta manera, en un importante desafío en las pacientes anoréxicas, producto de su intensa autoexigencia (Behar, 1996 \& Morandé, 1999).

Rowland (1980), citado en Behar (1996) señala que la similitud entre las pacientes anoréxicas y las obsesivas es la intensa ambivalencia de sus actos, el excesivo orden, la limpieza exhaustiva, el detallismo 
meticuloso, la testarudez, la rigidez, la necesidad de control y por supuesto, el perfeccionismo.

Las mujeres anoréxicas suelen ser extremadamente perfeccionistas, es típico que su desempeño académico sea sobresaliente y que sus padres las describan como hijas "modelos", muy colaboradoras, dóciles, sensibles ante el cuidado de sus padres y hermanos y con ausencia casi absoluta de rebeldía. Como parte de la perfección se encuentra el alcanzar una imagen ideal de delgadez, la cual nunca consiguen, debido a que la anoréxica jamás se verá a sí misma corporalmente perfecta. (Del Canto, 2001).

Rosa Behar, en el año 1996, realizó una investigación en la Región de Valparaíso, Chile, donde confirmó la hipótesis de Slade y Dewey (cit. en Behar, 1996), que planteaba que el perfeccionismo como rasgo aislado no es un factor significativo, pero unido a algún nivel de insatisfacción corporal, se transforma en un determinante amenazador para una eventual aparición de Anorexia Nerviosa.

Las relaciones que mantienen las pacientes anoréxicas suelen verse gravemente afectadas por la restricción emocional que presentan, la que se caracteriza por una dificultad para identificar y comunicar sus emociones, como también por una ausencia de respuesta afectiva (Asociación Americana de Psiquiatría, 1994). Todo lo anterior trae como consecuencia una dificultad para el desarrollo de relaciones de pareja duraderas y estables, debido a que son incapaces de establecer vínculos íntimos.

Un factor que cuenta con un respaldo favorable, basado en una serie de estudios sobre el tema, es el deficiente conocimiento interoceptivo, definido como la inhabilidad para discriminar estados emocionales de sí mismo (Leon \& cols., 1993, citados en Leon \& cols., 1995). En una investigación transversal, llevada a cabo por Leon \& cols., en el año 1993, se encontró que las mujeres con personalidad o temperamento caracterizadas por una pobre conciencia interoceptiva, presentaron alto riesgo de contraer Anorexia Nerviosa, tanto durante el primer como segundo año de la investigación.

Antecedentes existentes en la literatura señalan que el deficiente conocimiento interoceptivo o las dificultades en discriminar las señales de los propios impulsos corporales, es un poderoso factor etiológico en el desarrollo de los desórdenes alimenticios, extendiéndose desde la Anorexia Nerviosa hasta la obesidad (Bruch, 1969, citado en Leon \& cols., 1995). Este factor juega un papel importante en el desarrollo del trastorno, debido a que las adolescentes no son capaces de "escuchar a su propio cuer-

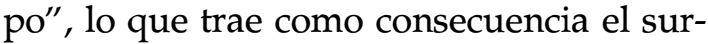
gimiento de conductas de riesgo para su propia salud y vida, debido a sus deseos incontrolables e irracionales de lograr "la figura perfecta". Sumado a esto y actuando como un factor que acrecienta y mantiene estos deseos e ideas irracionales, las anoréxicas reportan más síntomas, rasgos y preocupaciones que son mantenidos por los patrones obsesivos, los cuales se encontró, estaban relacionados con la vulnerabilidad a los desórdenes alimenticios y que se manifestaban principalmente en rituales y pensamientos persistentes (Rogers \& Petrie, 1996). Los mismos hallazgos fueron encontrados a nivel nacional, donde se aplicó EAT-26, versión abreviada del EAT-40², encontrándose que el Factor I (Dieta) de dicha escala es el más significativo predictor

2 El test de Actitudes Alimentarias (EAT40), fue creado por Garner y Garfinkel, en el año 1982, para detectar Anorexia Nerviosa y Bulimia. Durante el mismo año, Garner, Olmted, Bohr y Garfinkel, aplicaron la escala y sometieron cada uno de los ítems a un análisis factorial, identificando los 26 reactivos más significativos, a partir de los cuales elaboraron una versión abreviada de la escala original, denominada EAT 26. 
en cuanto a la capacidad de anticipar y confirmar una patología anoréxica. Este factor incluye la preocupación por obtener un perfil esbelto y la severa restricción de la ingesta, especialmente en relación con los hidratos de carbono (Behar, 1998).

La investigación de Leon \& cols. (1995) señala también que como factores de riesgo para el surgimiento de la Anorexia Nerviosa se pueden mencionar la falta de conciencia interoceptiva, relacionada con altos niveles de estrés y con formas negativas de emociones, como la depresión. Dentro de los mismos lineamientos, se plantea que la personalidad, junto con características temperamentales, son variables significativas al momento de establecer diferencias entre una dieta normal y patrones de desorden alimenticio más grave.

\section{Insatisfacción corporal}

Uno de los factores de riesgo más estudiados es la insatisfacción corporal, el cual se ve agravado por los marcados estándares sociales actuales que asignan una importancia fundamental a la delgadez. Morandé en 1999, precisó que un $45 \%$ de sus pacientes anoréxicas, presentaban una marcada insatisfacción, especialmente con sus muslos y nalgas. Lo anterior, sumado a la presencia de estados de ánimo negativos, puede conducir al uso y abuso anormal de los alimentos. Todo esto puede llevar a que con el paso del tiempo, estas conductas lleguen a ser aprendidas e instauradas en el repertorio conductual.

En un estudio longitudinal de 1 año de duración en adolescentes mujeres, se pudo encontrar que la imagen corporal negativa y las conductas dietéticas eran predictores significativos de conductas y actitudes alimenticias anormales (Attie \& Brooks-Gunn, 1989, cit. en Leon \& cols., 1995). Confirmando lo anterior, otra investigación prospectiva llevada a cabo en un grupo de adolescentes estudiantes de ballet, encontró que el descontento corporal y los deseos por adelgazar pueden pronosticar la presencia de desórdenes alimenticios (Garner \& cols., 1987, cit. en Leon \& cols., 1995).

A pesar de estos hallazgos, el descontento corporal tiene un riesgo variable significativo, por lo tanto, es importante poder identificar factores asociados que contribuyan a desarrollar y estabilizar los desórdenes alimenticios (Leon, Perry, Mangelsdorf \& Tell, 1989, citados en Leon \& cols., 1995).

Apoyando lo anterior, una investigación prospectiva encontró que la fortaleza predictiva del descontento corporal, en una misma población, va disminuyendo con el tiempo, ya que es una característica común tanto en adolescentes normales como con desórdenes alimenticios (Killen, Taylor, Telch, Saylor, Maron \& Robinson, 1986; Leon, Lucas, Colligan, Ferdinande \& Kamp, 1985, cit. en Leon \& cols., 1995). En nuestro país existen antecedentes similares que confirman dichas conclusiones, por lo cual no sería un fenómeno exclusivo de los desórdenes alimentarios, sino que más bien una condición que se debe presentar en complementariedad con otros factores, para constituir riesgo para el desarrollo de la Anorexia Nerviosa (Behar, Botero, Corsi, Muñoz \& Rosales, 1996).

\section{Creencias acerca de la delgadez}

Las adolescentes anoréxicas tienen la creencia que sus interacciones, están mediadas por la percepción que otros tienen de su cuerpo, obteniendo así, aprobación y estima. Igualmente, su autovaloración está fundada en estas mismas creencias, consecuentemente, sus esfuerzos están destinados a alcanzar el ideal de belleza corporal deseado. Si a esto agregamos rasgos obsesivos y la alteración de su percepción cor- 
poral, la adolescente anoréxica cae en una escalada por alcanzar el ideal propuesto.

Hoy en día, la sociedad plantea que el ideal es la delgadez, la cual debe ser conseguida sin importar los costos (Rausch \& Bay, 1997). La determinante social en la búsqueda de delgadez se puede observar en algo tan banal como la moda, la ropa esta diseñada y modelada para cuerpos delgados a pesar que pocas personas puedan usarlas (Del Canto, 2001). Además esta sociedad de consumo crea un modelo de delgadez que se vende como un producto más y siempre como sinónimo de éxito.

Por su parte, los medios de comunicación contribuyen con publicidad a forzar a la persona a igualar una apariencia física ideada culturalmente, mediante una construcción cognitiva, a costo de poner en peligro tanto su salud física como mental (Pulsomed, 2000).

Es por esta razón, que distintos investigadores han centrado su interés en factores socioculturales, principalmente debido a que existen creencias y actitudes de las mujeres con predisposición a desarrollar Anorexia Nerviosa, respecto a la imagen corporal $^{3}$. Según Wiseman, Gray, Mosimann y Ahrens (1992), citados en Rogers y Petrie (1996), la imagen socialmente ideal de belleza puede ser considerada como una causa fundamental de los desórdenes alimenticios. Así mismo, Rogers y Trent (1996), citados en Rogers y Petrie (1996), refieren que mujeres que viven en culturas que promueven en extremo la figura femenina estereotipada, pueden desarrollar trastornos alimenticios como forma de conducta, sin embargo, estos mismos autores señalan que enfocarse sólo en ideales de belleza, podría ser incompleto, debido a que la sociedad no sólo otorga un ideal de apariencia, sino también de comportamiento.

\section{Epidemiología de la Anorexia Nerviosa}

Basándose en la revisión de variadas investigaciones se ha encontrado que los índices de prevalencia a nivel mundial han aumentado considerablemente en las últimas décadas. En los años 60, la incidencia de Anorexia Nerviosa alcanzaba el 0,35\%, aumentado a un $0,64 \%$ en la década del 70 (Jones, Fox, Babigian \& Hutton, 1980, cit. en Belloch \& cols., 1995).

En el último decenio se estima que la prevalencia de la patología en mujeres adolescentes fluctúa alrededor del 1\% (Chinchilla, 1995; Kaplan \& Sadock, 1999 \& McCallum, 1993 cit. en Morandé, 1999).

En los Estados Unidos los trastornos alimenticios en adolescentes presentan una incidencia superior al 5\%, cifra que ha aumentado drásticamente en las últimas décadas (Kreipe \& cols., en prensa, cit. en Morandé, 1999).

En Madrid, la prevalencia del trastorno, en adolescentes de 15 años, entre los años 1985 y 1986 era de $0.3 \%$ y entre 1993 y 1994 las cifras aumentaron a un $0.68 \%$ (Morandé, 1999).

Una investigación llevada a cabo con estudiantes mujeres de $3^{\circ}$ y $4^{\circ}$ Años de Enseñanza Media, de establecimientos educacionales de la V Región de Chile, encontró que el $18 \%$ de las jóvenes podían ser incluidas dentro de la categoría de "potencialidad patológica" para el desarrollo de Anorexia Nerviosa. En un estudio posterior, realizado con un grupo universitario, se estimó que la posibilidad de evolución hacia una patología alimentaria era de un $15 \%$ y un $41 \%$ para las adolescentes portadoras de sobrepeso (Behar, Botero, Corsi \& Muñoz, 1994).

3 En esta orientación, nos parecen muy interesantes investigaciones como la de Botta (1999), quién estudia directamente la influencia de los medios de comunicación en la imagen corporal de jóvenes adolescentes. 
Del total de los casos diagnosticados con este trastorno, el $95 \%$ corresponde a mujeres y sólo el porcentaje restante a hombres (Kaplan \& Sadok, 1999), y se manifiesta frecuentemente entre los 10 y 30 años de edad. El riesgo de morbilidad para hermanas de anorécticas oscila entre un $6 \%$ a un $7 \%$ (Behar, 2000, citada en Heerlein, 2000).

La edad de inicio fluctúa entre los 13 y 18 años de edad (Belloch \& cols., 1995), por lo tanto, la población considerada de alto riesgo para desarrollar un trastorno anoréxico, lo constituyen las jóvenes adolescentes en edad escolar (Behar \& Cols., 1994), existiendo ciertos sectores más sensibles que otros, sobre todo aquellos que viven en países desarrollados y que poseen un alto status económico. Además, hoy en día su incidencia suele estar asociada a ciertas profesiones, tales como gimnastas y modelos (Kaplan \& Sadock, 1999)

\section{Objetivos}

\section{Objetivo General}

Determinar la influencia y relación existente entre factores individuales y familiares asociados al desarrollo de Anorexia Nerviosa en alumnas de Enseñanza Media , de la comuna de Concepción

\section{Objetivos Específicos}

1.- Establecer la relación existente entre los factores señalados por la literatura como asociados al desarrollo de anorexia nerviosa.

2.- Determinar el peso relativo de cada uno de los factores analizados en la presencia de desórdenes alimenticios.

\section{Método}

\section{Diseño}

El diseño de investigación empleado fue de tipo no experimental transversal descriptivo que intenta describir la relación entre las variables autoestima, depresión, cohesión familiar, adaptabilidad familiar , conflicto familiar, edad, peso, altura y tipo de establecimiento, y su influencia en el desarrollo de Anorexia Nerviosa.

\section{Sujetos}

La población corresponde a 12.250 alumnas de Enseñanza Media ${ }^{4}$, de la comuna de Concepción, compuesta por 9 Liceos Municipalizados, con una matricula total de 9.459 mujeres, 5 Colegios Particulares Subvencionados, con una matricula total de 1.229 mujeres y 11 Colegios Particulares con una matricula total de 1.562 mujeres.

Para seleccionar la muestra, la población fue dividida en estratos, utilizando dos criterios: tipo de establecimiento y niveles de Enseñanza Media, logrando establecer una distribución muestral proporcional a la población.

Se utilizó un muestreo por conglomerados bietápico. En la primera etapa, se obtuvo un primer grupo de conglomerados, constituidos por 7 Liceos Municipalizados, 5 Colegios Particulares Subvencionados y 6 Colegios particulares. En la segunda etapa se seleccionaron, aleatoriamente los niveles de Enseñanza Media de los establecimientos obtenidos en la primera etapa. Finalmente, de estos últimos conglomerados se procedió a extraer aleatoriamente las unidades finales, alumnas de los cursos seleccionados.

\footnotetext{
4 Al distribuir la población en tipos de establecimientos educacionales, se pretende establecer un símil con los estratos socioeconómicos, que cada uno de ellos representaría. Donde, colegios particulares = NSE alto, subvencionados particulares $=$ NSE medio y liceos municipalizados $=$ NSE medio - bajo .
} 
La muestra quedo construida como se muestra en la siguiente tabla.

Tabla 4.

Tamaño de la muestra por estratos

\begin{tabular}{lrc}
\hline & & Muestra \\
\hline ESTRATOS & $\mathrm{N}$ & $\mathrm{n}$ \\
Municipal & 9459 & 315 \\
Subvencionado & 1229 & 34 \\
Particulares & 1562 & 46 \\
TOTAL & 12250 & 395 \\
\hline
\end{tabular}

\section{Variables e instrumentos}

Para esta investigación las variables consideradas fueron Depresión y Autoestima (individuales), Cohesión, Adaptabilidad y Conflicto (familiares) y Edad, Peso, Altura y Tipo de establecimiento (sociodemográficas).

Para medir cada una de ellas se utilizó un set de instrumentos, los cuales fueron sometidos a una aplicación piloto para obtener datos de confiabilidad y validez, en el caso de que estos no existiesen para Chile. A continuación se enumeran los instrumentos, el número de itemes con que cuenta y los datos de confiabilidad y validez tanto de la prueba piloto como de la aplicación original.

\begin{tabular}{|c|c|c|c|c|c|c|}
\hline Escala & Autor & $\begin{array}{l}\text { № de } \\
\text { itemes }\end{array}$ & $\begin{array}{l}\text { Validez } \\
\text { original }\end{array}$ & $\begin{array}{c}\text { Confiabilidad } \\
\text { original }\end{array}$ & $\begin{array}{l}\text { Validez } \\
\text { Piloto }\end{array}$ & $\begin{array}{c}\text { Confiabilidad } \\
\text { Piloto }\end{array}$ \\
\hline $\begin{array}{l}\text { Escala de } \\
\text { Evaluación de } \\
\text { Adaptabilidad } \\
\text { y Cohesión } \\
\text { Familiar } \\
\text { FACES III }\end{array}$ & $\begin{array}{l}\text { Olson, } \\
\text { Portner \& } \\
\text { Lavee } 1987 .\end{array}$ & 20 ítems & $\begin{array}{l}0.68 \\
\text { (Florenzano, } \\
\text { 1995) }\end{array}$ & $\begin{array}{l}0.84 \\
\text { (Florenzano, } \\
\text { 1995) }\end{array}$ & 0.75 & 0.84 \\
\hline $\begin{array}{l}\text { Sub-escala de } \\
\text { Conflicto del } \\
\text { Inventario } \\
\text { Familiar de } \\
\text { Autoinforme } \\
\text { (SFI) }\end{array}$ & $\begin{array}{l}\text { Beavers \& } \\
\text { Hampson, } \\
1995\end{array}$ & 12 & $* * *$ & $* * *$ & -0.65 & 0.88 \\
\hline $\begin{array}{l}\text { Inventario de } \\
\text { Desordenes } \\
\text { Alimenticios } \\
\text { (EDI) }\end{array}$ & $\begin{array}{l}\text { Garner, } \\
\text { Olmstead \& } \\
\text { Polivy, } 1983 .\end{array}$ & 64 & $\begin{array}{l}0.56 \text { (Behar, } \\
1988 \text { ) }\end{array}$ & $* * *$ & $* * *$ & 0.88 \\
\hline $\begin{array}{l}\text { Escala de } \\
\text { Autoestima de } \\
\text { Rosenberg }\end{array}$ & $\begin{array}{l}\text { Rosemberg, } \\
\text { 1973, en } \\
\text { Arce, } 1994\end{array}$ & $\begin{array}{l}10 \\
\text { itemes }\end{array}$ & $\begin{array}{l}\text { de } 0.78 \\
\text { (Martínez } \\
\text { 1992, citado } \\
\text { en Cumsille } \\
\text { \& Ramírez, } \\
1999\end{array}$ & $\begin{array}{l}\text { entre un r: } \\
0.85 \text { y r: } 0.88 \\
\text { (Martínez } \\
\text { 1992, citado } \\
\text { en Cumsille \& } \\
\text { Ramírez, } 1999\end{array}$ & -0.47 & 0.91 \\
\hline $\begin{array}{l}\text { Inventario de } \\
\text { Depresión } \\
\text { Infantil (CDI), }\end{array}$ & $\begin{array}{l}\text { Kovacs, } \\
1992 .\end{array}$ & 27 & $* * *$ & $* * *$ & 0.82 & 0.86 \\
\hline
\end{tabular}




\section{Procedimiento}

Previo a la aplicación del instrumento, se solicito colaboración a cada establecimiento por medio de una carta. Una vez autorizados, se procedió a identificar las unidades muestrales. Al momento de la aplicación, los sujetos fueron retirados de sus salas de clases y trasladados a otra, dentro del mismo establecimiento, donde respondieron de una sola vez el total de los ítems del cuestionario.

El tiempo utilizado en responder, varió entre los 30 y 60 minutos, contando con la presencia de alguno de los autores de la investigación, cuya función era explicar el instrumento y aclarar las dudas que surgieron durante la aplicación.

\section{Análisis de Resultados}

\section{Análisis descriptivo}

A continuación se detallan los estadísticos descriptivos de las variables consideradas en la presente investigación.

Se presenta tamaño de la muestra, media y desviación estándar para cada una de las variables (Tabla 6), incluyendo aquellas medidas por las sub-escalas del instrumento EDI.

En el caso del puntaje en el EDI total por cada tipo de establecimiento, se presenta la media, desviación estándar de la escala, y valores mínimos y máximos (tabla 7).

Tabla 6.

Estadísticos descriptivos

\begin{tabular}{lccc}
\hline & $\mathrm{N}$ & Media & Desviación Estándar \\
\hline Edad & 398 & 16.7 & 1.25 \\
Peso & 398 & 55.4 & 8.44 \\
Altura & 398 & 1.6 & 0.06 \\
Cohesión & 397 & 38.7 & 7.29 \\
Adaptabilidad & 397 & 27.8 & 5.61 \\
Conflicto & 397 & 24.2 & 8.24 \\
Autoestima & 398 & 37.6 & 7.91 \\
Editot & 395 & 167.08 & 37.96 \\
Cditot & 395 & 41.3 & 7.04 \\
DI & 398 & 17.08 & 5.59 \\
ID & 396 & 18.9 & 8.06 \\
CI & 397 & 26.3 & 7.90 \\
BU & 397 & 14.2 & 5.68 \\
IC & 396 & 24.2 & 9.06 \\
Inefectividad & 397 & 22.9 & 8.49 \\
Temor & 397 & 23.6 & 5.47 \\
\hline
\end{tabular}


Tabla 7.

Puntaje en el EDI total por cada tipo de establecimiento

\begin{tabular}{lrlccc}
\hline & N & Media & $\begin{array}{c}\text { Desviación } \\
\text { Estándar }\end{array}$ & $\begin{array}{c}\text { Valor } \\
\text { mínimo }\end{array}$ & $\begin{array}{c}\text { Valor } \\
\text { máximo }\end{array}$ \\
\hline ESTABLECIMIENTO Tipo 1 & 315 & 169.2 & 37.34 & 94 & 273 \\
ESTABLECIMIENTO Tipo 2 & 34 & 166.5 & 41.90 & 96 & 279 \\
ESTABLECIMIENTO Tipo 3 & 46 & 152.7 & 36.85 & 93 & 261 \\
TOTAL & 395 & 167 & 37.96 & 93 & 279 \\
\hline
\end{tabular}

Aún cuando hemos informado los datos de media y desviación estándar de las subescalas del EDI (Eating Disorders Inventory), para el presente estudio se analizaran los resultados del EDI como escala total $^{5}$.

\section{Estadística bivariada}

A continuación se presentan las correlaciones entre las variables, utilizadas en la fase inicial del análisis. Para comenzar se debe decir que se encontraron correlaciones significativas en gran parte de las variables estudiadas, lo cuál se discutirá más extensamente en el apartado siguiente.

En este contexto las que mostraron una más alta correlación fueron autoestima y depresión, con un $r$ de Pearson de -0.728 , Depresión y Anorexia, con un $r$ de 0.710 y Autoestima y Anorexia, con un $r$ de -0.699 . El resto de las correlaciones se pueden observar en la tabla 8 .

En cuanto a la correlación entre Anorexia Nerviosa y las variables estudiadas, se evidencian como particularmente significativas, conflicto, cohesión y peso, con 0.406 , 0.289 y 0.285 , respectivamente. Estos resultados, así como los niveles de significancia para los estadísticos se presentan también en la tabla 8.

\section{Análisis multivariado}

Además del análisis bivariado, se llevó a cabo un análisis de regresión, para evaluar la posibilidad de predecir la anorexia a partir de las otras variables en estudio, considerando a esta como variable dependiente y a aquellas como independientes.

Para este análisis multivariado se presenta la siguiente ecuación inicial, para explicar la influencia de las variables independientes en la variable dependiente a analizar, según el marco teórico:

PUNTAJE EDI $=$ Constante + Establecimiento $2+$ Edad + Peso + Altura + Cohesión + Adaptabilidad + Conflicto + Autoestima + Depresión

Después de realizar el análisis de regresión, para especificar este modelo, la formula quedó compuesta de la siguiente manera:

PUNTAJE EDI = 121.319 (Constante) +2.21 (Depresión) - 1.68 (Autoestima) +1.16 (Peso) +0.71 (Conflicto) +0.58 (Cohesión) - 53.39 (Altura) - 7.85 (Establecimiento 2).

5 Este instrumento, en su versión original, no cuenta con puntaje de corte para la escala total; sin embargo, existen puntajes de corte por subescalas, los que no fueron utilizados para este estudio, por diferencias en la asignación de valores a las alternativas de respuesta. 
Tabla 8.

Coeficientes y niveles de significación para las variables incluidas en el modelo

\begin{tabular}{lrcccc}
\hline \multicolumn{2}{c}{ Coeficientes } & \multicolumn{2}{c}{$\begin{array}{c}\text { Coeficientes } \\
\text { estandarizados }\end{array}$} & & \\
& \multicolumn{1}{c}{ B estandarizados } & Error estándar & Beta & $\mathbf{t}$ & Sig. \\
\hline Constante & $\mathbf{1 2 1 . 3 1}$ & $\mathbf{3 7 . 3 3}$ & & 3.25 & $\mathbf{0 . 0 0 1}$ \\
Estable 2 & -7.85 & 3.62 & -0.06 & -2.16 & 0.031 \\
Peso & 1.16 & 0.15 & 0.25 & 7.34 & 0.000 \\
Altura & -53.39 & 22.25 & -0.08 & -2.40 & 0.017 \\
Cohesión & 0.58 & 0.22 & 0.11 & 2.61 & 0.009 \\
Conflicto & 0.71 & 0.19 & 0.15 & 3.65 & 0.000 \\
Autoestima & -1.68 & 0.21 & -0.35 & -7.70 & 0.000 \\
Depresión & 2.21 & 0.25 & 0.41 & 8.74 & 0.000 \\
\hline
\end{tabular}

Como se puede observar en la tabla, no fueron incluidas en la ecuación las variables Edad y Adaptabilidad, por presentar, en una primera aproximación un nivel de significancia bajo $(\mathrm{p}<0,05)$.

Tabla 9.

Análisis de varianza para la significación del ajuste del modelo final

\begin{tabular}{llrcccc}
\hline Modelo & Fuente & Suma de Cuadrados & g,L & Cuadrado Medio & f & Sig. \\
\hline 1 & Regresión & 361384.04 & 7 & 51626.29 & 99.35 & 0.000 \\
& Residual & 199022.22 & 383 & 519.64 & & \\
& Total & 560406.27 & 390 & & & \\
\hline
\end{tabular}

La capacidad predictiva del modelo resultante fue alta, explicando 0.64 de la variación total de la variable EDI ( $\mathrm{R}$ cuadrado).

El valor de ANOVA, arrojó un valor $F$ de 99.35, para 7 grados de libertad, lo cual es estadísticamente significativo.

Los establecimientos incluidos en la investigación, se agruparon en 3 categorías, siendo éstas, Liceos Municipalizados, Colegios Particulares Subvencionados y Colegios Particulares. Para los efectos del análisis, dichas categorías fueron consideradas como variables ficticias. Para establecer la existencia de diferencias entre grupos, se llevo a cabo un análisis de varianza que estableció un nivel de significación de 0.02, lo que indica la existencia de diferencias entre los tipos de establecimientos. Posteriormente, para determinar entre que categorías se produce la diferencia, se aplicó un test post hoc, que arrojó como resultado, que ésta se presentaba entre los Liceos Municipalizados y Colegios Particulares, la que es explicada por la diferencia significativa entre medias (16.47). Esto indica que los sujetos de la muestra, ubicados en los 
establecimientos municipales, presentan mayor riesgo de Anorexia Nerviosa.

\section{Análisis y Discusión}

Los hallazgos del presente estudio muestran una correlación significativa en la mayoría de las variables estudiadas, destacando principalmente la relación entre depresión $(r=0.71)$, autoestima $(r=-0.69)$, capacidad de resolución de conflictos familiares $(r=0.40)$ y la presencia de desórdenes alimenticios.

Si bien cada uno de los factores esta relacionado con los desórdenes alimenticios, mantener una visión aislada del peso relativo de cada variable en la manifestación del trastorno limita la comprensión de su etiopatogenia. Se sugiere leer la presente discusión desde una postura integrativa.

Una posible comprensión del modo en que interactúan dichos factores podría ser realizado, tomando elementos de algunas escuelas psicológicas. Postulados psicodinámicos ponen énfasis en la importancia de las experiencias tempranas y la relación que el niño establece con figuras significativas en su desarrollo individual y relacional. Si la relación vincular se caracteriza por inestabilidad y ambigüedad (o relaciones de apego inseguro) comenzará a desarrollar un Yo débil, dificultando una adaptación adecuada a las exigencias del entorno.

Así también, si el niño experimenta rechazo o ausencia de valoración genuina, se generan en el niño sentimientos de frustración. Al ser rechazados, criticados o abandonados, la autodepreciación se convierte al menos en un terreno fértil para que su autovaloración dependa exclusivamente de los demás. Al llegar la etapa de la adolescencia y junto a la necesidad de consolidar su identidad, cobra relevancia el nivel de autoestima desarrollada ya que ésta es, por lo menos en parte, un indicador del grado de satisfacción con la propia imagen y por ende, esta profundamente conectada con las valoraciones culturales en torno al cuerpo y a la belleza (Rausch \& Bay, 1997). Esta relación entre factores de vulnerabilidad generados en las relaciones objetales tempranas y desordenes alimenticios está sostenida por la literatura, donde se ha encontrado en distintas investigaciones que pacientes con trastornos alimenticios reaccionan afectivamente en forma más intensa a estimulos relacionados con la pérdida ( Becker, Bell \& Billington, 1987; Steiger y Houle, 1991), dificultades en la separaciónindividuación ( Friedlander \& Siegel, 1990), apego inseguro, y otras dimensiones similares. (cit. en Narduzzi \& Jackson, 2000) Lo anterior es coherente con, primero, algunas explicaciones psicodinámicas de la depresión, donde la identidad se relaciona con la autoestima y un Yo débil será más suceptible a sentimientos de autodepreciación, que puede estar dado por la excesiva dependencia de relaciones interpersonales (Depresión Anaclítica) o por una alta preocupación por el logro de metas que permitan la autodefinición en relación a sí mismo y los demás (Depresión Introyectiva). Segundo, algunos planteamientos de la terapia interpersonal, donde a partir de vínculos ambiguos e inestables se posibilita el desarrollo de factores de vulnerabilidad Intrapersonales e Interpersonales. Se debe señalar que esta Terapia ha informado porcentajes de efectividad de hasta un $90 \%$ en la reducción de síntomas (Narduzzi y Jackson, 2000). Finalmente, también es coherente con algunas conceptualizaciones acerca de la sociotropía y la dependencia en la depresión. Estos elementos, nos permitirían afirmar que la anorexia y la depresión presentan, a la base de su alta co-morbilidad, una base etipatogénica comun.

Por otra parte, las personas anoréxicas desarrollan principalmente su autoestima tomando como parámetros la aprobación 
externa y la apariencia física, por lo tanto, si el resultante de la evaluación que los otros realizan de ellas es desfavorable para sí o poseen algún grado importante de insatisfacción o descontento con su propio cuerpo, desarrollan una evaluación negativa de sí mismas, es decir, baja Autoestima. Confirmando lo encontrado en esta investigación Morandé (1999), señala que un 45\% de sus pacientes diagnosticadas con el cuadro clínico presentaban una marcada insatisfacción corporal. El análisis de la relación entre peso corporal y desórdenes alimenticios $(\mathrm{r}=0.28)$ indica que a mayor peso mayor es la probabilidad de padecer el trastorno. Estudios precedentes plantean el rol que juega la obesidad en la futura manifestación de la patología. Morandé (1999) encontró que el $10 \%$ de sus pacientes anoréxicas habían presentado obesidad previa al establecimiento del diagnóstico. Por otra parte, Behar \& cols. (1994) estimaron que el $41 \%$ de las adolescentes diagnosticadas con obesidad, podían manifestar a futuro, la patología. Nuestros hallazgos se encuentran en esta línea, en el sentido que el peso corporal tiene incidencia sobre el desarrollo de Anorexia Nerviosa, sin embargo, no se observa una estrecha relación con el resto de las variables predisponentes evaluadas, ya que su influencia podría estar más vinculada a características de personalidad medidas en las subescalas del $\mathrm{EDI}^{6}$. Se sugiere investigar con más precisión, el grado en que ciertos rasgos de personalidad, determinan la intensidad del deseo de las adolescentes de modificar su imagen corporal (Peña y Lillo, 1997).

A nivel familiar destaca como característica del funcionamiento del sistema, la escasa capacidad de resolución de conflictos familiares, manifestada desde los primeros años de vida del menor y que gene- ra un patrón de interacciones familiares. En consecuencia, si la percepción que la adolescente tiene del grado de manejo de situaciones conflictivas, por parte de su familia es negativa, mayor será la susceptibilidad a desarrollar la patología. En este sentido Rausch \& Bay (1997) postulan que las familias que funcionan como sistemas evitativos, no negocian explícitamente sus diferencias, por lo que éstas quedan sin solución, negando la existencia de problemas y generando la apariencia de "familia ideal", lo que además contribuye a favorecer la falta de conciencia de la adolescente sobre su problemática.

Otra variable en estudio corresponde al grado de cohesión familiar. En una primera interpretación, se encontró una correlación negativa $(r=-0.28)$, lo cual si bien está en concordancia con lo afirmado formalmente por la hipótesis, contradice lo señalado por las aproximaciones más sistémicas, ya que muestra que aquellas jóvenes, cuyas familias manifiestan una alta cohesión, en términos de apoyo y cercanía emocional, presentan menor riesgo de padecer un desorden alimenticio. Este hallazgo por sí solo, similar a los encontrados por Humprhrey \& Stern, en 1988 y algunos otros autores (cit. en Laliberté \& cols., 1999), merece un análisis más exhaustivo.

Para efecto de este estudio, la cohesión fue medida a través de la escala FACES III, basada en el modelo circumplejo de Olson ${ }^{7}$. Esta escala no cuenta con puntajes de corte disponibles para determinar, por ejemplo que familias funcionan de una manera patológicamente sobreinvolucrada. Por lo tanto, sería necesario clasificar a las jóvenes en el continuo correspondientedel modelo original, para iluminar los hallazgos desde un punto de vista teórico. 
En términos estadísticos, como se ha dicho, cuando el análisis se realiza desde una perspectiva correlacional, la relación entre Cohesión y Anorexia Nerviosa es negativa. Sin embargo, resulta interesante que al realizar el análisis multivariado, la relación se invierte $(B=0.58)$, indicando que a mayor grado de Cohesión del sistema familiar mayor es la probabilidad de manifestar un cuadro anoréxico. Esto puede ser identificado al realizar una depuración con cada una de las variables, para explicar el cambio de dirección que adquiere la relación en el modelo predictivo final, concluyendo que es la variable Depresión la que determina tal cambio. Es decir, en términos gráficos, la curva que vincula las variables anorexia y cohesión está inclinada debido al peso estadístico que ejerce el grupo de adolescentes más depresivas. Esto podría ser entendido, como que la adolescente depresiva, tiende a concentrar un mayor apoyo de su familia que el resto de la muestra.

Además, a partir del análisis de varianza realizado, podemos señalar que existen diferencias significativas entre los Liceos Municipalizados y los Colegios Particulares en relación al puntaje obtenido en la escala de Desórdenes Alimentarios. Para identificar con precisión cual de estas dos dependencias administrativas determina la diferencia, se hizo necesario profundizar el análisis a través de un Test Post Hoc, que estableció que los Liceos presentaban el promedio más alto de desórdenes alimentarios. Esto significa que, si bien es cierto no estamos en condiciones de determinar la prevalencia de la patología, podemos afirmar que la muestra proveniente de los establecimientos municipales, poseen el mayor nivel de predisposición.

De acuerdo a lo mencionado, la hipótesis de trabajo establecida para este factor debe ser rechazada, ya que nuestra premisa presuponía una relación estrecha entre Desorden Alimentario y establecimientos particulares, entendidos estos como representantes de un estrato socioeconómico alto. Si bien es cierto, que se podría esperar una distribución uniforme en la manifestación de los desórdenes alimentarios en los distintos estratos socioeconómicos, es importante destacar que en el presente estudio se evidenció una mayor presencia del trastorno en niveles socioeconómicos bajos, representados por los Liceos Municipales. Una posible explicación de este fenómeno apunta al hecho que, aún cuando ambos sectores están expuestos a los mismos estímulos y presiones sociales (fuerte influencia de los medios de comunicación, estereotipos sociales de belleza, competitividad, exigencias familiares, entre otros), la diferencia radica en la mayor vulnerabilidad y riesgo que podrían manifestar las adolescentes de estratos bajos (presencia en conjunto de características depresivas, baja autoestima, sobrepeso, baja capacidad de resolución de conflictos familiares y sobreinvolucramiento afectivo), lo cual conlleva a que presenten niveles de prevalencia mayor que en grupos de colegios particulares.

Introduciéndonos en el análisis multivariado propiamente tal, la presente investigación procuró elaborar un modelo para predecir la presencia o al menos el riesgo de Desórdenes Alimentarios, a partir de la conjunción de ciertas variables independientes, proporcionando tres factores principales: Depresión, Autoestima y Peso. Además de estas tres variables iniciales se presentan como relevantes en la predicción, el conflicto familiar y la cohesión. En la medida en que presentaron una relación inversa, entenderemos que aumenta el riesgo de padecer un Desorden Alimentario, la percepción de conflicto y la carencia de apoyo y/o sobreinvolucramiento familiar. Completando la formula, se encuentran las variables altura y colegio municipal, que en su conjunto nos permite afirmar que el modelo explica en un $64 \%$ la predicción de Desórdenes Alimentarios. 
En consecuencia, si lo antes expuesto fuese entendido como un perfil de riesgo, nuestro modelo podría asemejarse a los factores predisponentes señalados por Morandé (1999) y Toro \& Vilardell (1987, citados en Belloch \& cols., 1995), quienes además señalan perfeccionismo, aparente autonomía, introversión/estabilidad, familias muy sensibles a las apariencias, familiares con adicción o trastornos de ingesta, obesidad materna y valores estéticos dominantes. Aquí es necesario recordar, analizar y comparar resultados con investigaciones como la de Laliberté \& Cols. (1999), quienes señalan que no son los factores familiares clásicos (cohesión, conflicto y expresión emocional), como lo investigados aquí, los que distinguen la aparición de trastornos alimenticios de otros trastornos generales, sino más bien otros como preocupación de la familia por la apariencia y el peso, por las apariencias sociales, por el rendimiento. Se debe señalar que la investigación mencionada también establece semejanzas muy interesantes en el funcionamiento familiar de adolescentes depresivas y anoréxicas.

Al interpretar los resultados de estas investigaciones a partir de nuestros hallazgos, podemos afirmar que los factores analizados y mencionados anteriormente (presencia en conjunto de características depresivas, baja autoestima, sobrepeso, baja capacidad de resolución de conflictos familiares y sobreinvolucramiento afectivo ) establecen un perfil de vulnerabilidad general sobre el cual variables como perfeccionismo, preocupación por la apariencia , el peso y por las apariencias sociales, actúan a menudo (y no excluyendo $a$ priori eventos traumáticos tales como el abuso), como gatillantes.

\section{Conclusiones}

En la investigación realizada, se considera relevante destacar a modo de conclusión lo siguiente:

1) Existen relaciones significativas obtenidas en el análisis bivariado, que permiten confirmar las hipótesis, estableciendo correlaciones directamente proporcionales entre Depresión $(r=$ $0.71)$, Conflicto $(r=0.40)$, Peso $(r=$ $0.28)$ y Altura $(r=0.09)$ con Desórdenes Alimentarios. En el análisis bivariado, se encontraron correlaciones inversamente proporcionales entre Autoestima $(r=-0.69)$ y Cohesión $(r=-0.28)$ con los Trastornos Aliemtarios. Estos resultados merecen un análisis más profundo.

2) Al pasar al análisis multivariado, los factores Edad y Adaptabilidad no fueron incluidos en el modelo final, rechazándose las hipótesis de trabajo correspondientes, por presentar, en una primera aproximación, un bajo nivel de significancia $(p<0,05)$.

3) La hipótesis referida a la relación entre Colegios Particulares y Trastornos Alimentarios, fue rechazada, debido a que el análisis estadístico realizado, comprobó mayor presencia del trastorno en los Liceos Municipalizados.

4) La presente investigación plantea, a prtir de los resultados y conclusiones, que los factores analizados en establecen un perfil de vulnerabilidad general no específico para la anorexia.

5) La formula final del análisis, en términos predictivos, permite afirmar que el modelo explica en un $64 \%$ la predicción de Desórdenes Alimentarios en la muestra, valor que puede extrapolarse a la población $(\mathrm{F}=99.35)$. 
6) En consecuencia, la información obtenida, sugiere la necesidad de investigar la relación entre Depresión - Desórdenes Alimentarios; la articulación entre Factores Individuales y Familiares (especialmente cohesión y aquellos no incluidos en la presente investigación) en el desarrollo de dichos desórdenes y vincular el Peso Corporal con características de personalidad, que posibiliten el aumento de su valor predictivo.

7) Finalmente, resultaría interesante disponer del EDI, por su alto valor predictivo, como una herramienta clínica, que permita identificar, en la población, sujetos con alto riesgo de presentar manifestaciones clínicas de Desórdenes Alimentarios. Para esto, se recomienda realizar una investigación que permita estandarizar el instrumento en nuestro país.

\section{Referencias}

Ajuriaguerra, J. (1997) Manual de Psiquiatría Infantil, 4ํ Edición. Barcelona: Masson.

Arce, C. (1994) Técnicas de construcción de escalas psicológicas. Editorial Síntesis, Psicología. Colección Metodología de las ciencias del comportamiento. Madrid.

Asociación Americana de Psiquiatría (1994) Manual de Diagnóstico y Estadística de Desordenes Mentales, $4^{\circ}$ Edición. Washington: APA.

Beavers, W. \& Hampson, R. (1995) Familias Exitosas. Evaluación, Tratamiento e Intervensión. Madrid: Ediciones Paidós Ibérico.

BEHAR, R. (1986) Trastornos del hábito del comer en población riesgosa. Un estudio preliminar. Revista Médica de Valparíso, Vol 39 (№ 4): 166-177.
Behar, R., Botero, J., Corsi, P. \& Muñoz, P. (1994) Detección de trastornos del hábito del comer en una población estudiantil de la V región. Revista Chilena de NeuroPsiquiatría. (№ 32): 159-165.

Behar, R., Fernández, W., Rumie, K. \& VARELA, C. (1996) Trastornos del hábito del comer en un grupo de estudiantes universitarios. Análisis exploratorio. Revista de Psiquiatría. Vol 13 (№1): 12-16.

Behar, R., Botero, J., Corsi, P., Muñoz, P. \& Rosales, R. (1996) Insatisfacción corporal en los trastornos del hábito del comer. Revista de Psiquiatría. Vol 12 (№2): 67-73.

BEHAR, R. (1996) El perfeccionismo en los trastornos del hábito del comer. Revista Chilena de Neuropsiquiatría. (№34):257262.

BEHAR, R. (1998) Trastornos del hábito del comer en adolescentes: aspectos clínicos y epidemiológicos. Revista Médica de Chile. (№ 126): 1085-1092.

BeHAR, R. (2000) Trastornos de la conducta alimenticia. En: A. Heerlein [Edit] Psiquiatría clínica (pp: 457-488). Santiago, Chile: Ediciones de la Sociedad de Neurología y Cirugía.

BeHAR, R. (2001) Contacto personal (3/12/ 2001).

Belloch, A., Ramos, F. \& SANDANI, B. (1995) Manual de Psicopatología, V. 1, 1ํEdición. Madrid: McGraw Hill.

BotтA, R. (1999) Television images and adolescent girls body image disturbance. Journal of communication. 49 (2)

Cumsille, P. \& Ramírez V. (1999) Evaluación de un programa comunitario destinado a favorecer el desarrollo psicosocial de madres adolescentes y sus hijos. Psykhe, Vol 8 (N²): 17-29. 
Chinchilla, A. (1995) Guía teórico-práctica de los trastornos de la conducta alimenticia: Anorexia Nerviosa y Bulimia Nerviosa. Barcelona: Masson.

Del Barrio, V., Moreno-Rosset, C. \& LópezMartínez, R. (1999) El Children's Depression Inventory, (CDI; Kovacs, 1992). Su aplicación en población española. Clínica y salud, Vol 10 (№ 3): 393416.

Del Canto, C. (2001) Trastornos de la alimentación. Anorexia y Bulimia Nerviosa. http:/ /members.es.tripod.de/Karlita/ (23/ 04/2001).

DíAZ, J. (2001) Anorexia y Bulimia.org. Paidos Psiquiatría, Unidad de Salud Mental Infanto - Juvenil, Almería, España. Http://w.w.w.anorexiaybulimia.org (2/ $12 / 2001$ )

Dorr, O. (1995) Psiquiatría Antropológica: contribuciones a una psiquiatría de orientación fenomenológica-antropológica, $1^{\mathrm{o}}$ Edición. Santiago: Universitaria.

FERNÁNDEZ-BALLESTEROS, R. (1994) Evaluación Conductual hoy: un enfoque para el cambio en psicología clínica y salud, 1o Edición. Madrid: Pirámide.

Florenzano, R. (1995) Familia y salud de los jóvenes. Santiago: Ediciones Universidad Católica de Chile.

Garner, D. Olmstead, M.\& Polivy, J. (1983) Development and validation of a multidimensional eating disorder inventory for anorexia nervosa and bulimia. International Journal of Eating Disorders, Vol 2 (№ 2):15-34.

Guidano, V. (1994) El sí mismo en proceso. Hacia una terapia cognitiva post-racionalista. Buenos Aires: Paidos Ibérica.
Heatherton, T., Mahamedi, F., Striepe, M., Field, A. \& Keel, P. (1997). A 10 year longitudinal study of body weight, dieting and eating disorder symptoms. Journal of Abnormal Psychology, Vol 106 ( $\mathrm{N}^{\mathrm{o}}$ 1): $117-125$.

Kaplan, H. \& SADOCK, B. (1992) Tratado de Psiquiatría, Tomo II, 2o Edición. Barcelona: Sadock.

Kaplan, H. \& Sadock, B. (1992) Sinopsis de Psiquiatría. Ciencias de la Conducta. Psiquiatría Clínica, 8o Edición. Madrid: Editorial Médica Panamericana.

Klump, K., McGue, M. \& IAcono, W. (2000). Age differences in genetic and environmental influences on eating attitudes and behaviors in preadolescent and adolescent female twins. Journal of Abnormal Psychology, Vol 109 (№2): 239251.

Laliberté, M., Boland, F. \& Leichner, P. (1999) Family Climates: Family factors specific to disturbed eating and bulimia nervosa. Journal of Clinical Psychology. Vol 55 (no 9).

Leon, G., Fulkerson J., Perry, Ch., \& Cudeck, R. (1993). Personality and behavioral vulnerabilities associated with risk status for eating disorder in adolescent girl. Journal of Psychology, Vol 102 (№3): 438444.

Leon, G., Fulkerson, J., Perry, Ch. \& EarlyZALD, M. (1995). Prospective analysis of personality and behavioral vulnerabilities and gender influences in the later development of disorder eating. Journal of Abnormal Psychology, Vol 104 (N ${ }^{\mathrm{o}}$ 1): $140-149$.

LUDEWIG, K. (1990) Un enfoque sistémico al problema psicosomático ejemplificado en la Anorexia en adolescentes. En Terapia Psicológica, Vol 9 (№ 13): 31-42. 
Marsellach, G. (2000) La anorexia y la bulimia. El psicólogo en la red. http:// ciudadfutura.com/psico/artículos / trastornos_alimentarios.htm (19/04/ 2000).

Morandé, G. (1999) Conductas de riesgo en adolescentes, Trastornos por hacer dieta. Anorexias y Bulimias Nerviosas. Psykhe, Vol. 8 (№ 2): 31-42.

Narduzzi, K. \& Jackson, T. (2000) Personality Differences between EatingDisordered Women and a Nonclinial Comparison Sample: A Discriminant Classification Analysis. Journal of Clinical Psychology. 56 (6)

Ollendick, T. \& Hersen, M. (1993) Psicopatología Infantil, 1ํㅡㄹ Edición. Barcelona: Martínez Roca.

Organización Mundial de la SAlud. (1992) Décima Revisión de la Clasificación Internacional de enfermedades, trastornos mentales $y$ del comportamiento. Madrid: Meditor.

PeÑa y Lillo, S. (1997) La manía de adelgazar, 2 Edición. Santiago, Chile: Universitaria.

Pérez, M., Schifferli, P. \& Vielma, A. (2000) Perfil psicométrico de la mujer trabajadora temporera de la $8^{\underline{a}}$ región. Seminario para optar al título de licenciado en psicología. Escuela de Psicología, Universidad San Sebastián, Chile.

Ponce, E., Gómez F., Irigoyen A., Terán M., Landgrave S., Montesinos, M. \& Hernández, M. (1999) Análisis de la confiabilidad de FACES III (versión en español). Atención Primaria en http:// db.doyma.es / cgi-bin/wdbcgi.exe/ doyma/mrevista.fulltex?pident=14820. Publicación Oficial de la Sociedad Española de Medicina de Familia y Comunitaria. (18/07/2001).

Pulsomed (2000) Anorexia Nerviosa. Sanitas. http: / / www.tuotromedico.com/temas/anorexia.htm (20/02/2000).

Rausch, C. y BAy, L. (1997) Anorexia Nerviosa y Bulimia: amenazas a la autonomía, $1^{\circ}$ Edición. Buenos Aires: Paidós.

Rogers, R. y Petrie, T. (1996). Personality correlates of anorexic symptomatology in female undergraduates. Journal of Counseling \& Development, Vol 75: 138143.

Sáiz, P., González, M., Baskaran, M., FernándeZ, J., Bousoño, M. Y Bobes, J. (1999) Prevalencia de trastornos de conducta alimenticia en jóvenes de enseñanza secundaria: un estudio preliminar. Acta Esp Psiquiatría, Vol 27 (№ 6): 367374.

Stice, E., Hayward, Ch., Cameron, R., Killen, J. Y TAYLOR, C. (2000) Body - Image and eating disturbances predict onset of depression among female adolscents: A longitudinal study. Journal of Abnormal Psychology, Vol 109 (№ 3): 438 - 444.

WONDERLICH, S. y MitCHELL, J. (2001). The role of personality in the onset of eating disorders and treatment implications. The Psychiatric Clinics of North America, Vol 24 (№ 2): 249-258. 
